Supplement of Clim. Past, 15, 2053-2065, 2019

https://doi.org/10.5194/cp-15-2053-2019-supplement

(c) Author(s) 2019. This work is distributed under

the Creative Commons Attribution 4.0 License.

(c) (1)

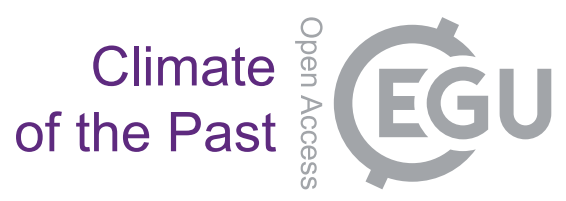

Supplement of

\title{
Two types of North American droughts related to different atmospheric circulation patterns
}

\author{
Angela-Maria Burgdorf et al. \\ Correspondence to: Angela-Maria Burgdorf (angela-maria.burgdorf@giub.unibe.ch)
}

The copyright of individual parts of the supplement might differ from the CC BY 4.0 License. 


\section{Supplementary Material}

\section{S1 | "Dust Bowl"-type droughts}
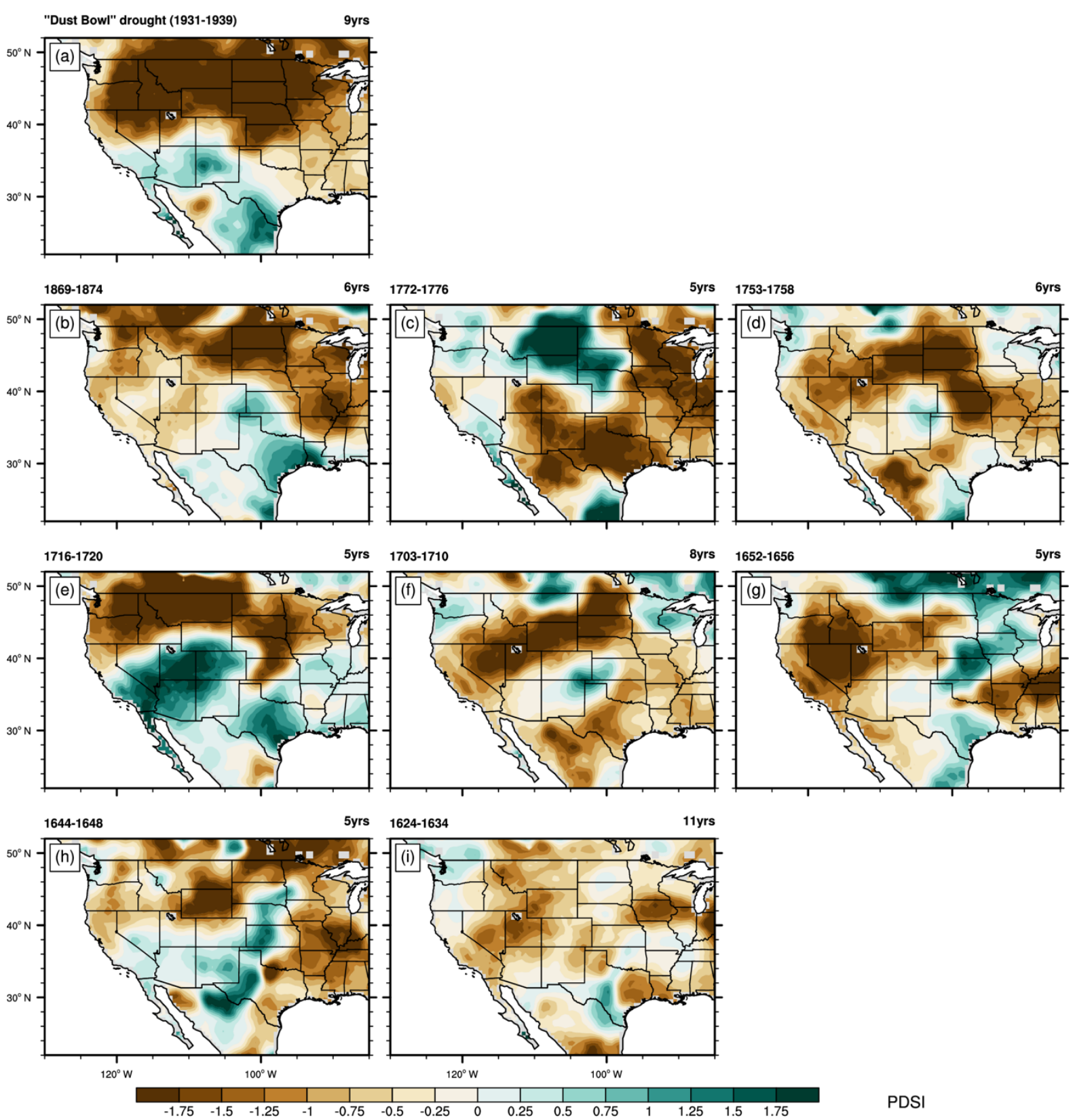

PDSI

Figure S1. Averaged PDSI values from the LBDAv1 for the "Dust Bowl" drought (a) and the eight droughts classified as "Dust Bowl"-type droughts (b-i). 


\section{S2 | 1950s-type droughts}
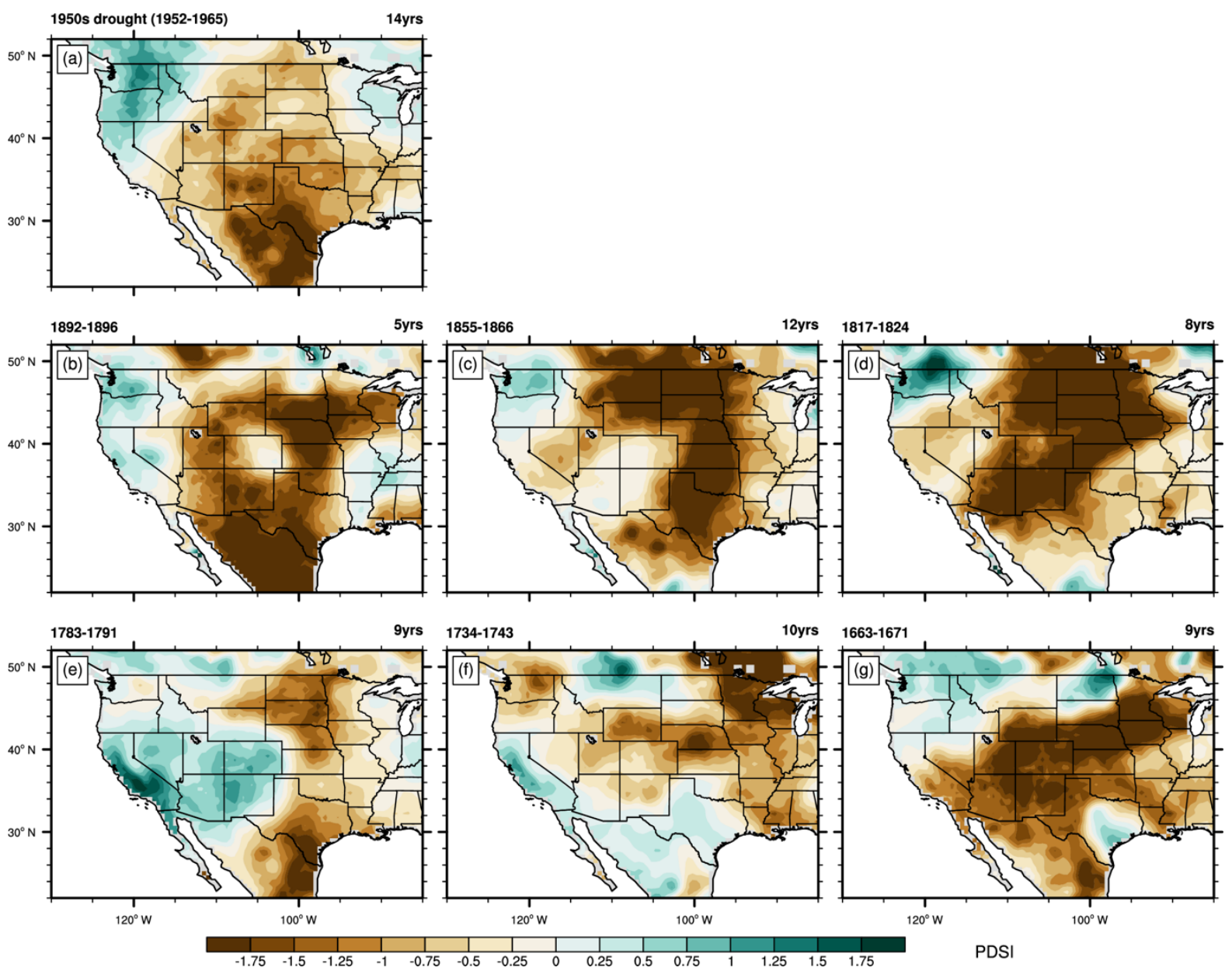

Figure S2. Averaged PDSI values from the LBDAv1 for the 1950s drought (a) and the six droughts classified as 1950s-type droughts (b-g). 


\section{S3 | Drought clustering: ward}

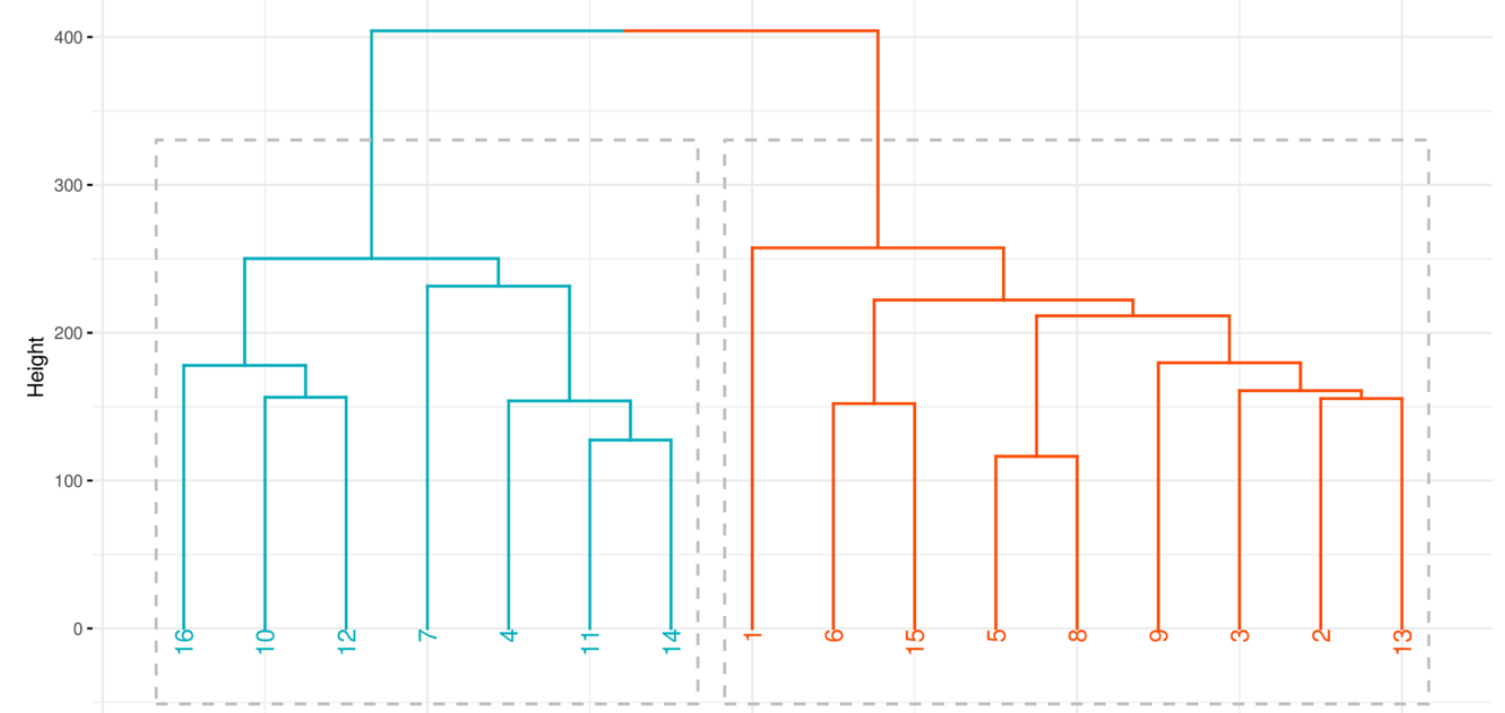

Figure S3. First two principal components of the hierarchical clustering based on the ward method of PDSI values for the 16 drought periods.

\section{S4 | Drought clustering: combined approach k-means \& ward}

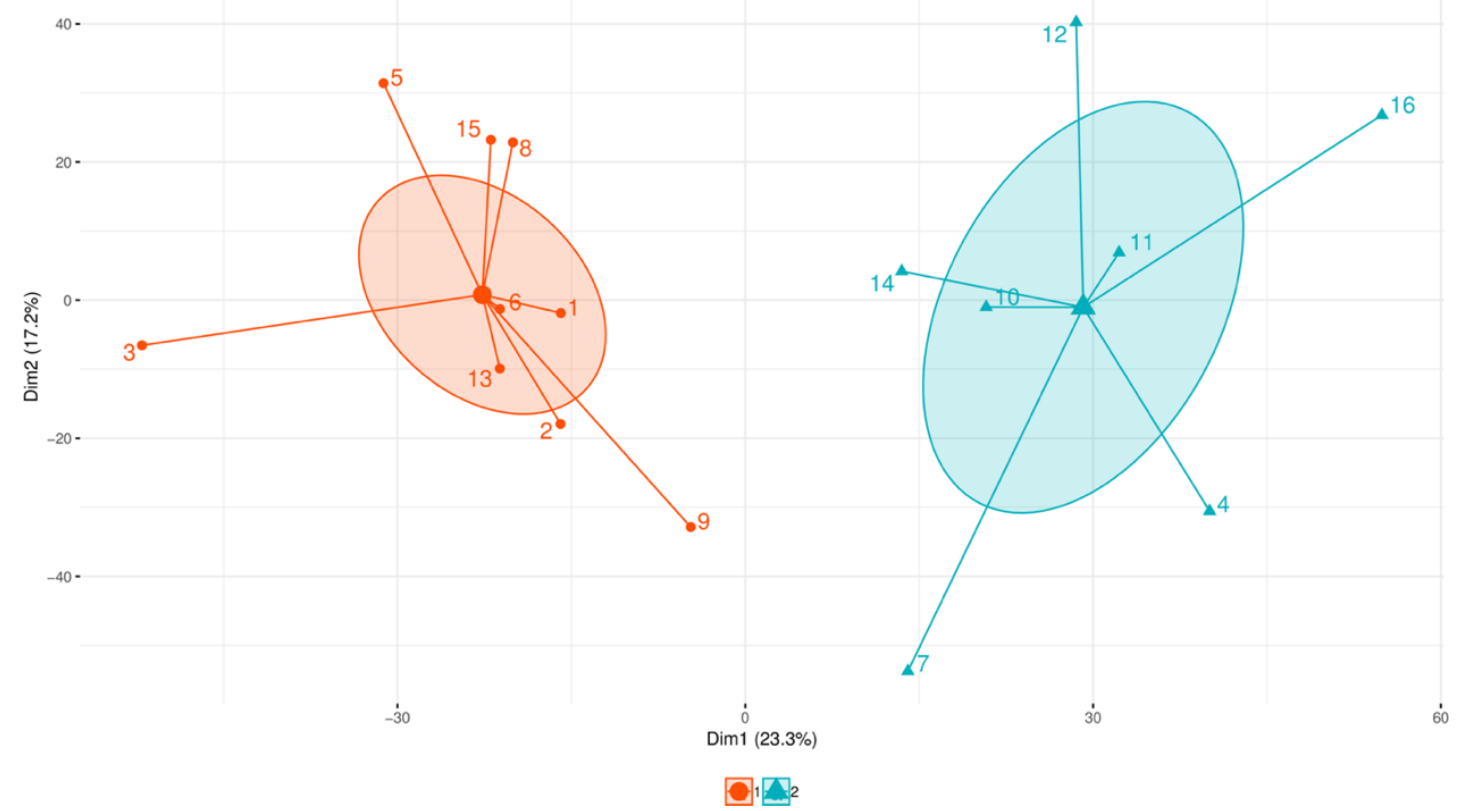

Figure S4. First two principal components of PDSI values for the 16 drought periods based on the k-means clustering approach with prescribed cluster centers (defined by the previous experiment with the ward method). 


\section{S5 | Correlation of the Turn-of-the-century drought}

(a) Turn-of-the-century drought vs. Dust Bowl-type drought

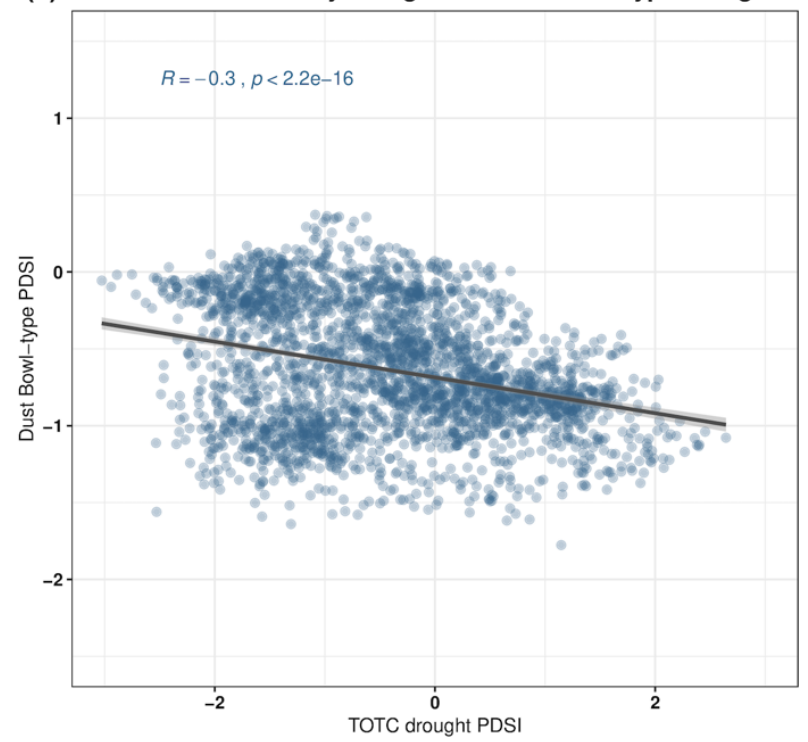

(b) Turn-of-the-century drought vs.1950s-type drought

Figure S5. Correlations (Pearson) between the turn-of-the-century drought and the "Dust Bowl"-type drought (a) and between the turn-of-the-century drought and the 1950s-type drought respectively (b). Each point depicts a grid box. 


\section{S6 | SLP composites}

SLP Composites relative to $1604-2000$ climatology

"Dust Bowl"-type drought

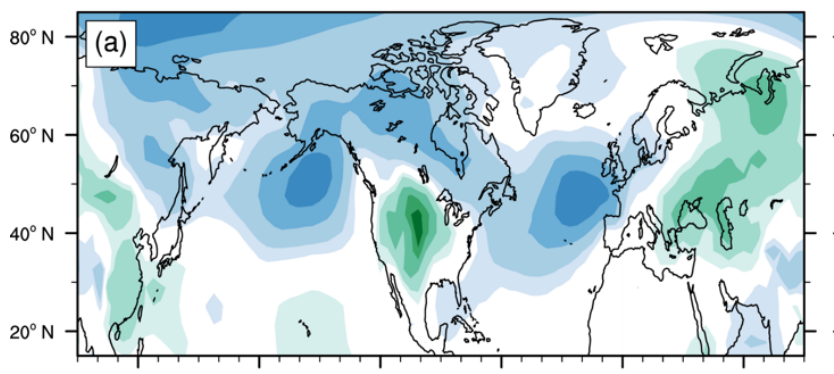

1950s-type

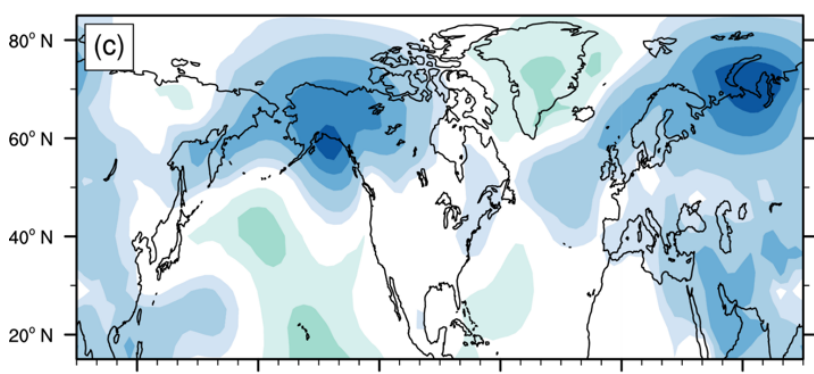

Difference ("Dust Bowl"-type - 1950s-type)

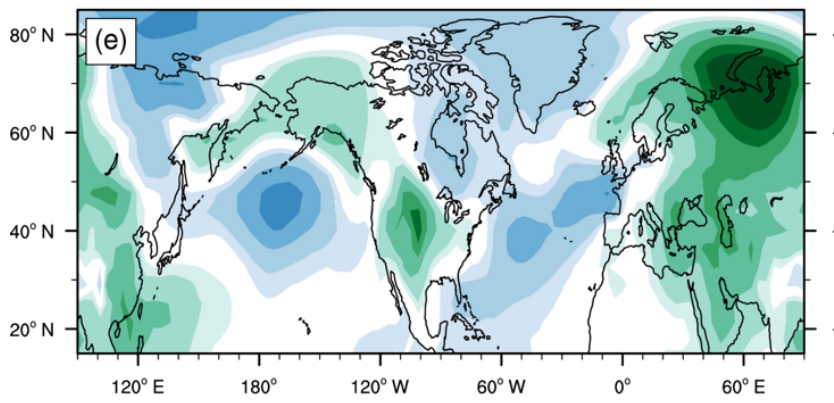

SLP composites

"Dust Bowl"-type drought

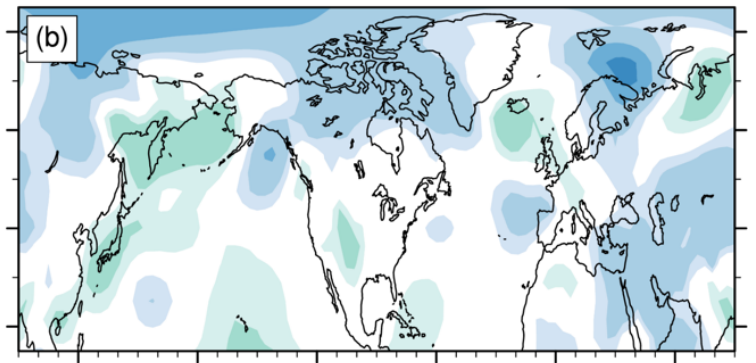

1950s-type

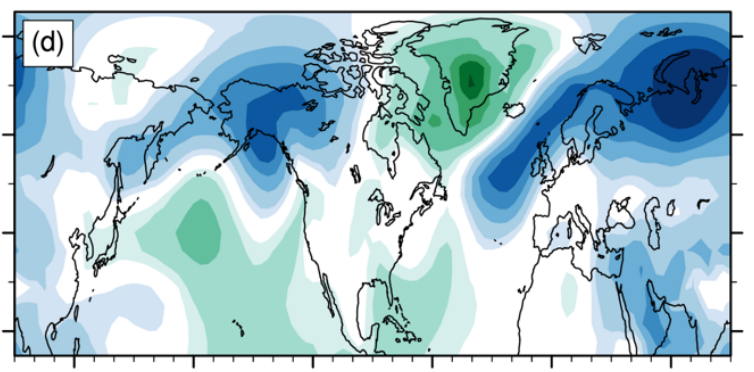

Difference ("Dust Bowl"-type - 1950s-type)

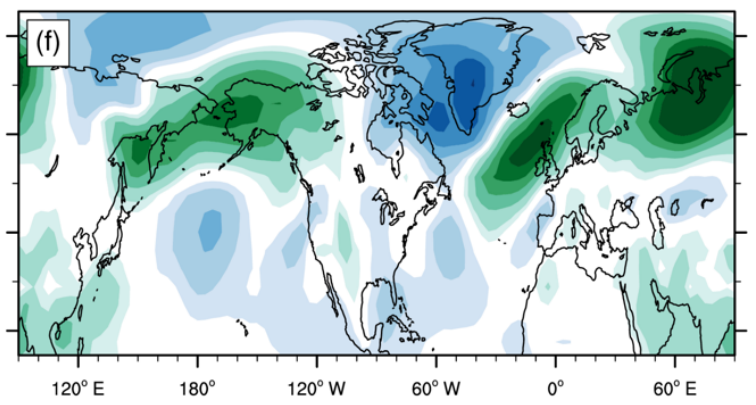

$\begin{array}{llllllllllll}-0.5 & -0.4 & -0.3 & -0.2 & -0.1 & -0.05 & 0.05 & 0.1 & 0.2 & 0.3 & 0.4 & 0.5\end{array}$

$\mathrm{hPa}$

Figure S6. SLP composites relative to the 1604-2003 long-term mean (a, c, e) and the composites relative to the 5 yrs periods prior and after the drought $(\mathbf{b}, \mathbf{d}, \mathbf{f})$. The top row depicts the SLP composites of the "Dust Bowl"-type droughts, the middle row the 1950s-type droughts and the bottom row the difference between the two drought types. 


\section{S7 | Surface temperature composites}

EKF400 T2m droughts JJA
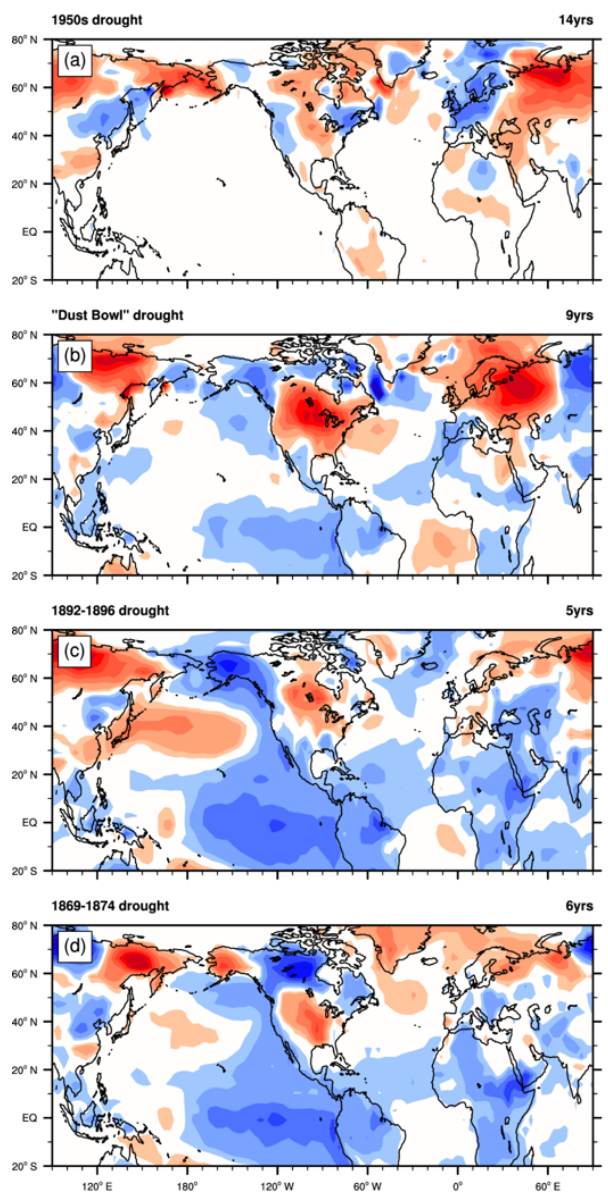

PHYDA T2m droughts JJA

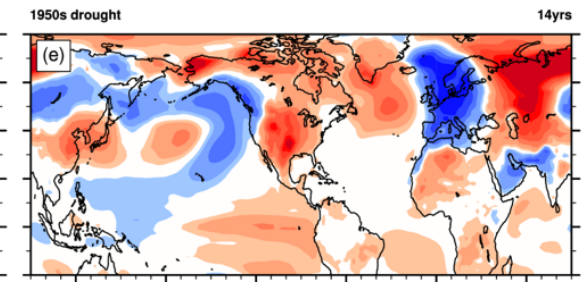

1950s drought

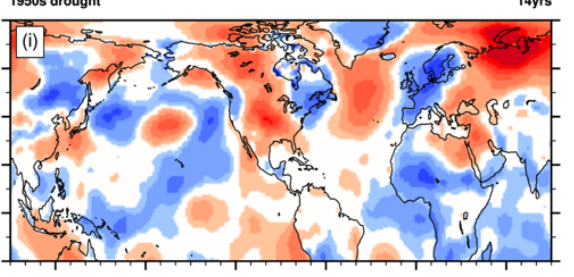

9yrs "Dust Bowl" drought
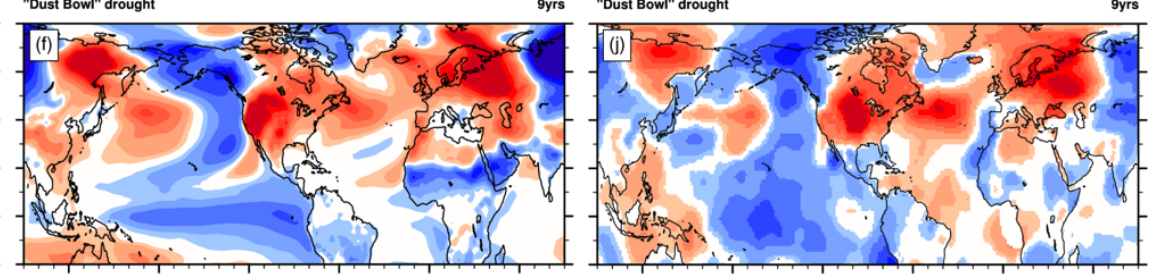

5yrs 1892-1896 drought
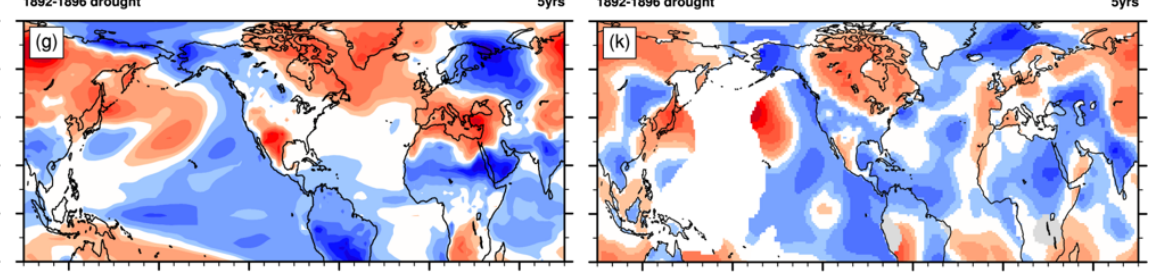

1869-1874 drought

Gyrs $\quad 1869-1874$ drought
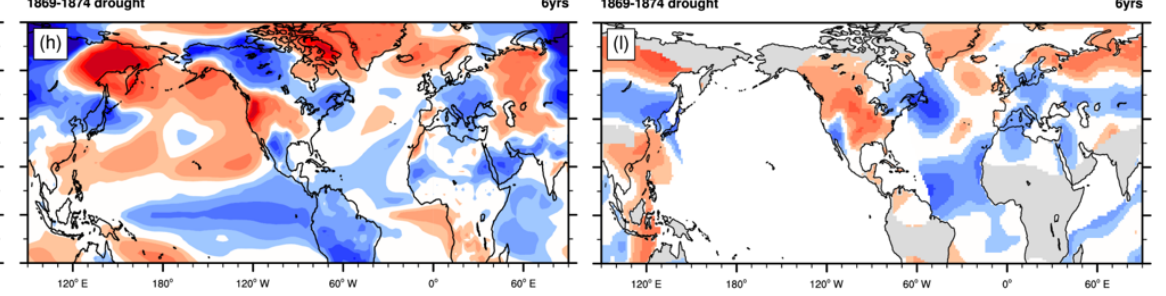

$\begin{array}{llllllllllllll}-1.2 & -1 & -0.8 & -0.6 & -0.4 & -0.2 & -0.1 & 0.1 & 0.2 & 0.4 & 0.6 & 0.8 & 1 & 1.2\end{array}$ 
20CRv2c T2m droughts JJA
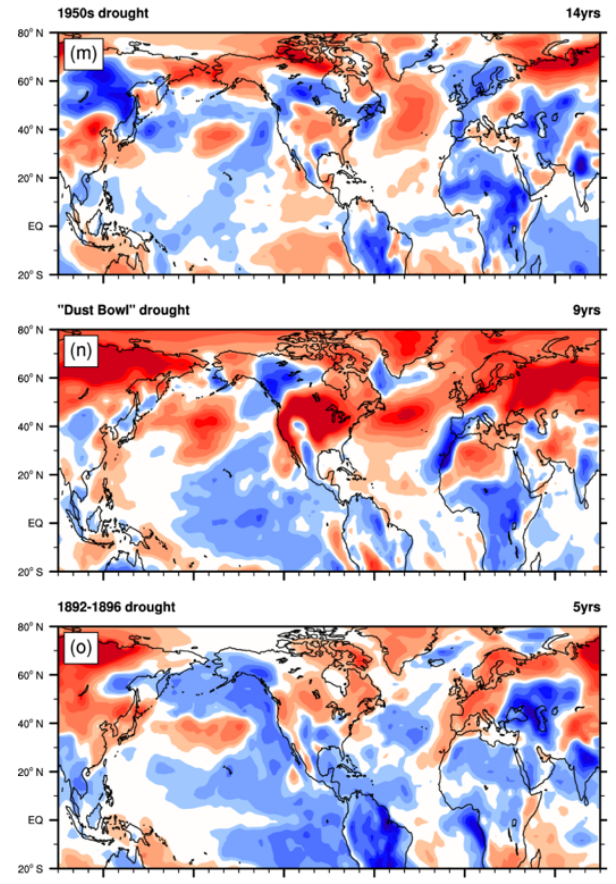

Syrs

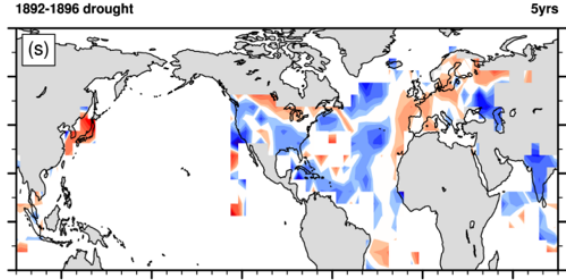

6yrs $\quad 1869-1874$ drought
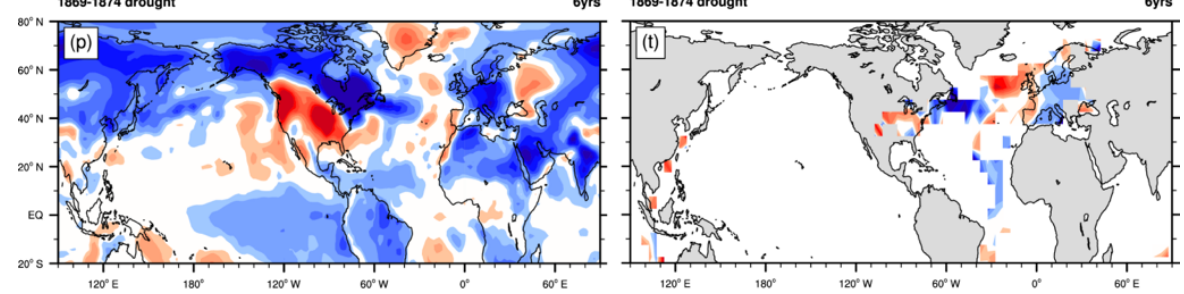

HadCRUT4.6 T2m droughts JJA
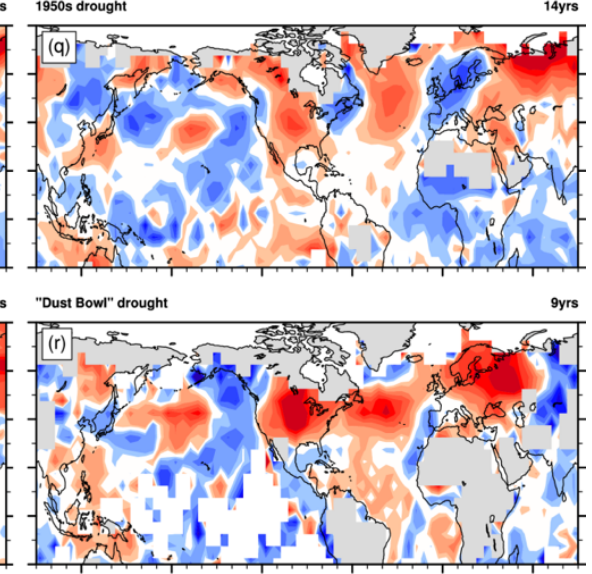

$\begin{array}{cccccccccccccc}-1.2 & -1 & -0.8 & -0.6 & -0.4 & -0.2 & \begin{array}{c}-0.1 \\ {[\mathrm{deg}]}\end{array} & 0.2 & 0.4 & 0.6 & 0.8 & 1 & 1.2\end{array}$

Figure S7. Surface temperature composites in five different datasets for the latest four droughts, the 1950s drought (top row), the "Dust Bowl" drought (second row), the 1892-1996 drought (third row) and the 1869-1874 drought (bottom row). The T2m of the two paleo reconstructions EKF400 (a-d) and PHYDA (e-h) are shown as well as the surface air temperature from the observational products Berkeley Earth (i-l) and HadCRUT6.4 (q-t) and additionally, the $\mathrm{T} 2 \mathrm{~m}$ from the 20CRv2c reanalysis (m-p). 


\section{Table S1 Comparison of Fye et al. (2003) and our study}

Table S1. Comparison of our clustering approach with the droughts found by Fye et al. (2003). "Dust Bowl"-type droughts are marked with dark shading, 1950s-type droughts with light shading. Overlapping droughts were attributed to each other.

\begin{tabular}{|c|c|c|c|}
\hline Fye et al. (2003) & Our study & $\mathbf{N}_{\text {drought years }}$ & Cluster \\
\hline $1946-1958$ & $1952-1965$ & 14 & 2 \\
\hline $1929-1940$ & 1931-1939 & 9 & 1 \\
\hline \multicolumn{4}{|l|}{$1897-1904^{+}$} \\
\hline & $1892-1896$ & 5 & 2 \\
\hline $1870-1883$ & $1869-1874$ & 6 & 1 \\
\hline $1855-1865$ & $1855-1866$ & 12 & 2 \\
\hline \multicolumn{4}{|l|}{$1841-1848$} \\
\hline $1818-1824$ & $1817-1824$ & 8 & 2 \\
\hline \multicolumn{4}{|l|}{$1805-1814$} \\
\hline & $1783-1791$ & 9 & 2 \\
\hline $1772-1782$ & $1772-1776$ & 5 & 1 \\
\hline $1752-1760 *$ & $1753-1758$ & 6 & 1 \\
\hline \multicolumn{4}{|l|}{$1752-1757^{*}$} \\
\hline \multirow[t]{2}{*}{$1728-1744$} & $1734-1743$ & 10 & 2 \\
\hline & $1716-1720$ & 5 & 1 \\
\hline $1703-1712$ & $1703-1710$ & 8 & 1 \\
\hline \multirow[t]{3}{*}{$1663-1672$} & $1663-1671$ & 9 & 2 \\
\hline & $1652-1656$ & 5 & 1 \\
\hline & $1644-1648$ & 5 & 1 \\
\hline $1626-1634^{*}$ & $1624-1634$ & 11 & 1 \\
\hline $1622-1628^{*}$ & & & \\
\hline
\end{tabular}

${ }^{+}$Given the 5-yr moving average used in the definition, these droughts might be considered the same.

* These two droughts overlap in Fye et al. (2003). 